\title{
Artaud e seus duplos: A sombra de Sêneca
}

\section{Artaud and his doubles: The shadow of Seneca}

Rafael Guimarães Tavares da Silva ${ }^{1}$ 


\section{Resumo}

Este artigo busca explorar a relação entre o pensamento de Antonin Artaud e as tragédias de Sêneca, sugerindo sua importância para o desenvolvimento de certa vertente da dramaturgia contemporânea. Apoiando-nos na fortuna crítica recente sobre esses autores, voltamos a documentos fundamentais desse debate, a fim de sugerir de que forma a leitura revitalizante da obra trágica de Sêneca vem a ser operada por Artaud. Acreditamos que os desdobramentos de suas considerações sobre sangue [cruor] e corpos em cena são importantes não apenas em práticas e teorias renovadas do teatro, mas também em algumas das considerações modernas sobre as origens ritualísticas do drama.

Palavras-chave: Artaud; Sêneca; Teatro da Crueldade; dramaturgia; recepção clássica

\section{Abstract}

This article intends to explore the relation between the thought of Antonin Artaud and the tragedies of Seneca, suggesting its importance to the development of a certain strand of contemporary dramaturgy. Relying on the recent critical fortune on these authors, we return to fundamental documents of this debate, in order to suggest how the revitalizing reading of Seneca's tragic works is operated by Artaud. We believe that the unfolding of his considerations about blood [cruor] and bodies in scene are important not only in renewed theater theories and practices but also in some of the modern considerations about the ritualistic origins of drama.

Keywords: Artaud; Seneca; Theatre of Cruelty; dramaturgy; classical reception studies 
A história da recepção da obra trágica de Sêneca desde fins da Idade Média até a contemporaneidade é atravessada por juízos ambíguos, nos quais o reconhecimento de sua qualidade retórica e de sua influência dramática se vê muitas vezes mitigado por acusações de artificialismo e verborragia. ${ }^{2}$ Um capítulo fundamental dessa história é aquele inaugurado pelas leituras que Antonin Artaud, o célebre dramaturgo francês e criador da ideia de Théâtre de la Cruauté [Teatro da Crueldade], propõe a partir das tragédias senequianas, destacando o caráter fundamentalmente cruento e revitalizante de suas peças. Contrapondo-se às interpretações que a partir do início do século XIX, sobretudo da perspectiva filológica alemã, se tornaram majoritárias no contexto universitário europeu, com sua depreciação do legado latino, em prol de uma valorização da cultura helênica, ${ }^{3}$ o dramaturgo francês revela certas vias de pesquisas para a obra de Sêneca que viriam a ser exploradas com importantes desdobramentos para uma consideração mais escrupulosa de suas propostas dramáticas e poéticas. Antes, porém, de definir as particularidades dessa recepção, será necessário avançar algumas considerações gerais sobre as ideias de teatro e drama para o autor francês, tal como esboçadas principalmente em Le théâtre et son double [O teatro e seu duplo]. ${ }^{4}$

Antonin Artaud abre seu principal livro teórico com um texto em tom de manifesto intitulado "Le théâtre et la culture [O teatro e a cultura]". Partindo da constatação da falência da cultura ocidental e da tentativa atual desesperada por parte dos pedagogos de reconstruí-la, o autor sugere que seria preciso extrair da cultura aquelas ideias cuja força viva fosse idêntica à da fome. Na sua concepção, a cultura moderna se faz passar por uma espécie de acessório sofisticado, quando na verdade apenas apelando ao caráter visceral da cultura seria possível ultrapassar os limites da mera necessidade utilitária e chegar àquilo que de fato importa. Mas o homem moderno teria destruído o divino, bem como a poesia e tudo o mais que poderia dar vida à existência humana. Diante desse estado de coisas, sua proposta é a seguinte:

Se o teatro é feito para permitir que nossos recalques ganhem vida, um tipo de poesia atroz exprime-se por atos bizarros nos quais as alterações do fato de se viver demonstram que a intensidade da vida está intacta e que bastaria dirigi-la melhor.

Mas por mais que reivindiquemos a magia, no fundo temos medo de uma vida que se desenvolveria inteiramente sob o signo da verdadeira magia. (Artaud, 1964d, p. 14) ${ }^{5}$

Artaud acredita ser necessário operar um retorno à natureza, a fim de encontrar mais uma vez a vida. "Podemos queimar a biblioteca de Alexandria [On peut brûler la bibliothèque d'Alexandrie]" (Artaud, 1964d, p. 15). Contra uma ideia de arte passiva - espiritual e contemplativa -, ele defende que a verdadeira cultura deve se fazer no

\footnotetext{
${ }^{2}$ Para detalhes do longo e complexo processo de recepção do Sêneca tragicus ao longo da história, cf. Dodson-Robinson, 2016.

${ }^{3}$ Para detalhes desse momento, cf. Citti, 2016, p. 255-6.

${ }^{4}$ Todas as traduções de textos escritos em língua estrangeira são de minha responsabilidade (a menos quando especificado o nome de outro tradutor). Para 0 caso dos textos de Sêneca, dei preferência para as traduções existentes em português (com exceção do texto da peça Thyestes, cuja tradução não pude encontrar), acrescentando sempre o respectivo texto latino na nota de rodapé (Sêneca, 1921; 1986).

${ }^{5}$ Si le théâtre est fait pour permettre à nos refoulements de prendre vie, une sorte d'atroce poésie s'exprime par des actes bizarres où les altérations du fait de vivre démontrent que l'intensité de la vie est intacte, et qu'il suffirait de la mieux diriger./ Mais si fort que nous réclamions la magie, nous avons peur au fond d'une vie qui se développerait tout entière sous le signe de la vraie magie. (Tradução nossa)
} 
corpo e no sangue. ${ }^{6}$ Contra a ideia tradicional de um teatro em que cada apresentação aspira a ser sempre a mesma, seria necessário atentar para a sombra que duplica toda performance: os gestos, os movimentos dos corpos, os objetos, os ruídos, os cheiros, em suma, a corporalidade da cena - tudo aquilo que resiste a tornar-se ideia abstrata. Artaud acusa o teatro ocidental de uma verborragia esvaziada e, ainda que ele pretenda ser herdeiro antes de Sêneca do que dos tragediógrafos gregos, boa parte de sua crítica certamente seria aplicável também à tragédia retórica do poeta latino. ${ }^{7}$ Seu ataque àquilo que - pelo menos desde os trabalhos de Jacques Derrida ${ }^{8}$ - poderia ser chamado de logocentrismo no pensamento ocidental fica evidente numa passagem como esta, em que afirma o seguinte:

A fixação do teatro com uma linguagem - palavras escritas, música, luzes, ruídos - indica com pouco atraso sua perda, a escolha de uma linguagem provando o gosto que se tem pelas facilidades dessa linguagem; e o ressecamento da linguagem acompanha sua limitação.

Para o teatro, como para a cultura, a questão permanece a de nomear e dirigir as sombras: e o teatro, que não se fixa na linguagem e nas formas, destrói por aí as falsas sombras, mas prepara a via a um outro nascimento de sombras em torno das quais se forma o verdadeiro espetáculo da vida. (Artaud, 1964d, p. 18-9) ${ }^{9}$

Em outro texto, "Le théâtre et la peste [O teatro e a peste]", contudo, a aproximação com Sêneca talvez comece a se tornar mais explícita. Trabalhando a analogia entre teatro e peste, o autor faz uma crítica à forma como a peste foi abordada tradicionalmente em certos escritos (históricos, religiosos e mesmo medicinais), antes como uma espécie de manifestação exterior cujos traços mórbidos teriam mais impacto nos espíritos do que nos corpos (Artaud, 1964e, p. 25). Ora, o interesse de Artaud é justamente pela morbidez corporal que se manifesta numa situação de calamidade pública iniciada por uma Peste. A partir de sua visão, a aproximação que se deve fazer entre o teatro - tal como ele o compreende - e a Peste encontra-se justamente aí: o teatro, na hora da performance, é a Peste que se instala numa cidade. O ator é um portador da Peste. Espetáculo do horror, transposição do possível, o teatro deve revelar o fundo de crueldade a partir do qual são extraídas as forças da própria vida. Segundo Artaud:

\footnotetext{
${ }^{6}$ Sobre a "crueldade" desse teatro, vale a pena levar em conta a ressalva de um comentador contemporâneo: "[l]n Artaud's gnomic musings 'cruelty' meant not simply stage violence and bloodshed but a different metaphysics of the theater in which the spectator's dream world, his hidden obsessions and fantasies, would pour forth upon the stage in a new language of mise-en-scène, blasting away a bankrupt aesthetics of realism and mere psychology. For Artaud, this project of a theater that connected deeply to an inexpressible primal scene - a theater existing "only on a level that is not yet human" - was literally refigured by the "monsters" of Senecan drama (he refers in particular to Thyestes) who are "wicked as only blind forces can be". (Remshardt, 2016, p. 286)

${ }^{7}$ O próprio autor, contudo, está consciente da herança de uma racionalidade latina por parte do Ocidente. É o que se evidencia quando escreve: « Et en opposition avec cette façon de voir, façon qui me paraît à moi tout occidentale ou plutôt latine, c'est-à-dire butée, je dirai que dans la mesure où ce langage part de la scène, où il tire son efficacité de sa création spontanée sur la scène, dans la mesure où il se bat directement avec la scène sans passer par les mots (et pourquoi n'imaginerait-on pas une pièce composée directement sur la scène, réalisée sur la scène), - c'est la mise en scène qui est le théâtre beaucoup plus que la pièce écrite et parlée. On va me demander sans doute de préciser ce qu'il y a de latin dans cette façon de voir opposée à la mienne. Ce qu'il y a de latin, c'est ce besoin de se servir des mots pour exprimer des idées qui soient claires. Car pour moi les idées claires sont, au théâtre comme partout ailleurs, des idées mortes et terminées. »(Artaud, 1964a, p. 60-1).

${ }^{8}$ Para uma interessante exposição da possível relação entre o trabalho de Artaud e a crítica ao logocentrismo ocidental, cf. Derrida, 1967a.

${ }^{9}$ Et la fixation du théâtre dans un langage: paroles écrites, musique, lumières, bruits, indique à bref délai sa perte, le choix d'un langage prouvant le goût que l'on a pour les facilités de ce langage; et le desséchement du langage accompagne sa limitation./ Pour le théâtre comme pour la culture, la question reste de nommer et de diriger des ombres: et le théâtre, qui ne se fixe pas dans le langage et dans les formes, détruit par le fait les fausses ombres, mais prépare la voie à une autre naissance d'ombres autour desquelles s'agrège le vrai spectacle de la vie. (Tradução nossa)
} 
Podemos dizer que toda a verdadeira liberdade é negra e se confunde inevitavelmente com a liberdade do sexo que também é negra, sem que se saiba bem por quê. Pois há muito tempo o Eros platônico, o senso genésico, a liberdade de vida, desapareceu sob o revestimento sombrio da Libido que se pode identificar com tudo o que há de sujo, abjeto, infamante no fato de viver, de se precipitar com um vigor natural e impuro, com uma força sempre renovada em direção à vida.

E é assim que todos os grandes Mitos são negros e que não se pode imaginar fora de uma atmosfera de carnificina, de tortura, de sangue derramado, todas as magníficas Fábulas que contam às multidões sobre a primeira partilha sexual e a primeira carnificina de essências que aparecem na criação. (Artaud, 1964e, p. $44-5)^{10}$

Com essa longa citação talvez comece a ficar claro em que sentido Artaud se pretenda um herdeiro das tragédias de Sêneca. Aqui vale a pena evocar algumas passagens impressionantes dos textos senequianos a fim de tornar ainda mais explícita essa sugestão. Em Troades [As troianas], um mensageiro conta o seguinte a Andrômaca:

Mas que restos o precipício

permitiu que sobrassem? Os ossos espalhados e despedaçados

com a violência da queda, os traços do corpo ilustre,

o semblante e as conhecidas feições de seu nobre pai,

o peso do tombo confundiu no fundo do abismo;

o pescoço quebrou-se no choque com as pedras, a cabeça

abriu-se, saindo o cérebro para fora. É um corpo

sem formas que jaz.

(Troades, vv. 1110-7, trad. Zélia de Almeida Cardoso). ${ }^{11}$

\section{Em Oedipus [Édipo], é mais uma vez o mensageiro quem conta o seguinte:}

Ardem as ameaçadoras faces com fogo atroz

e os olhos mal se contêm em suas órbitas;

violento, temerário semblante, irado, feroz,

somente preocupado em escavar os olhos; geme e, de modo terrível bramindo, as mãos contra o rosto volta. Mas seus ferozes olhos puseram-se-lhes no caminho e, dirigidos para suas mãos, por si mesmos as seguiram e vão ao encontro de sua ferida.

Perscruta ávido com seus dedos recurvos os olhos e ao mesmo tempo do fundo das raízes inteiramente arranca os seus globos; agarra-se ao vazio a mão e, fixa no fundo, com as unhas lacera profundamente os cavos recessos dos olhos e as esvaziadas cavidades, e encoleriza-se em vão e mais do que o necessário se enfurece.

(Oedipus, vv. 958-70, trad. Giovani Roberto Klein). ${ }^{12}$

\footnotetext{
${ }^{10}$ On peut dire maintenant que toute vraie liberté est noire et se confond immanquablement avec la liberté du sexe qui est noire elle aussi sans que l'on sache très bien pourquoi. Car il y a longtemps que l'Éros platonicien, le sens génésique, la liberté de vie, a disparu sous le revêtement sombre de la Libido que l'on identifie avec tout ce qu'il y a de sale, d'abject, d'infamant dans le fait de vivre, de se précipiter avec une vigueur naturelle et impure, avec une force toujours renouvellée vers la vie./ Et c'est ainsi que tous les grands Mythes sont noirs et qu'on ne peut imaginer hors d'une atmosphère de carnage, de torture, de sang versé, toutes les magnifiques Fables qui racontent aux foules le premier partage sexuel et le premier carnage d'essences qui apparaissent dans la création. (Tradução nossa)

${ }^{11}$ NUNTIUS. Quos enim praeceps locus/ reliquit artus? ossa disiecta et graui/ elisa casu; signa clari corporis,/ et ora et illas nobiles patris notas,/ confudit imam pondus ad terram datum;/ soluta ceruix silicis impulsu, caput, / raptum cerebro penitus expresso-iacet/ deforme corpus.

${ }^{12}$ ardent minaces igne truculento genae/ oculique uix se sedibus retinent suis;/ uiolentus audax uultus, iratus ferox,/ tantum furentis; gemuit et dirum fremens/ manus in ora torsit, at contra truces/ oculi steterunt et suam intenti manum/ ultro insecuntur, uulneri occurrunt suo./ scrutatur auidus manibus uncis lumina,/ radice ab ima funditus uulsos simul/ euoluit orbes; haeret in uacuo manus/ et fixa penitus unguibus lacerat cauos/ alte recessus luminum et inanes sinus,/ saeuitque frustra plusque quam satis est furit.
} 
Seria possível evocar muitos outros exemplos, tão ou ainda mais cruentos do que esses, como a descrição do sacrifício dos filhos de Tiestes por Atreu (Thyestes, vv. 720-9), a morte dos próprios filhos em cena, por Medeia, na peça homônima (Medea, vv. 963-1027), ou a forma como é narrado o massacre perpetrado por Hércules contra os próprios filhos, em Hercules furens (vv. 974-1053). Certamente haveria pelo menos um exemplo por peça. Mas aqui não interessa a Artaud entrar nas razões - filosóficas, morais ou poéticas - que teriam levado Sêneca a representações tão cruéis em suas tragédias: a crueldade está ali, em cena, materializada na hipotipose de um discurso tornado materialmente pleno. É isso o que lhe interessa na obra desse autor, pois: "Tudo o que age é uma crueldade. É sobre essa ideia de ação levada às últimas consequências, extrema, que o teatro deve renovar-se" (Artaud, 1964b, p. 132). ${ }^{13}$

Como foi recentemente colocado por um estudioso da recepção de Sêneca entre diretores do séc. XX, a visão de Artaud era certamente excêntrica, ainda mais quando se leva em conta que era a Fedra de Racine que ainda ditava as regras da tragédia na França de então (Remshardt, 2016, p. 286). Mas em sua crítica justamente ao psicologismo raciniano do teatro francês contemporâneo, Artaud evoca "um tipo de lirismo horrendo que se encontra nos Mitos" forjados pelas coletividades massivas (Artaud, 1964b, p. 133), ${ }^{14}$ embora não se trate aí de um mero retorno a esses "Mitos". Sua utilização exaustiva pela tradição teatral do Ocidente foi responsável por esvaziá-los e seu desejo seria antes retomar sua força primitiva para injetar de novo vida em suas performances:

Eis por que, à volta de personagens famosos, de crimes atrozes, de entregas sobre-humanas, tentaremos concentrar um espetáculo que, sem recorrer às imagens expiradas dos velhos Mitos, revele-se capaz de extrair as forças que se agitam neles.

Numa palavra, acreditamos que há, no que se chama poesia, forças vivas, e que a imagem de um crime apresentada nas condições teatrais necessárias é para o espírito algo de infinitamente mais temível do que esse mesmo crime, realizado. (Artaud, 1964b, p. 133). ${ }^{15}$

Há, portanto, um retorno aos temas dos "velhos Mitos", mas sem uma atitude passiva perante a tradição que os legou. Com relação a isso, vale observar que as propostas de Artaud almejam renovar o teatro por meio do emprego daquilo que seria da ordem da mais absoluta presença: sua recusa ao texto escrito, ${ }^{16}$ bem como seu apelo ao gesto, ao grito, ao objeto, não são mais do que manifestações de seu desejo por uma experiência total de contato - sem barreiras entre a cena e o público. ${ }^{17}$ Aqui não

\footnotetext{
${ }^{13}$ Tout ce qui agit est une cruauté. C'est sur cette idée d'action poussée à bout, et extrême que le théâtre doit se renouveler.

${ }^{14}$ [...] cette sorte d'affreux lyrisme qui est dans les Mythes auxquels des collectivités massives ont donné leur consentement. (Tradução nossa)

${ }^{15}$ C'est pourquoi, autour de personnages fameux, de crimes atroces, de surhumains dévouements, nous essaierons de concentrer un spectacle qui, sans recourir aux images expirées des vieux Mythes, se révèle capable d'extraire les forces qui s'agitent en eux./ En un mot, nous croyons qu'il y a, dans ce qu'on appelle la poésie, des forces vives, et que l'image d'un crime présentée dans les conditions théâtrales requises est pour l'esprit quelque chose d'infiniment plus redoutable que ce même crime, réalisé. (Tradução nossa)

${ }^{16}$ Em um de seus "manifestos", Artaud escreve o seguinte: «Nous ne jouerons pas de pièce écrite, mais autour de thèmes, de faits ou d'oeuvres connus, nous tenterons des essais de mise en scène directe. La nature et la disposition même de la salle exigent le spectacle et il n'est pas de thème, si vaste soit-il, qui puisse nous être interdit.» (Artaud, 1964c, p. 151).

${ }^{17}$ Esses aspectos são explicitados em outros trechos do supracitado "manifesto". Acerca do público, ele comenta apenas: «ll faut d'abord que ce théâtre soit.» (Artaud, 1964c, p. 153).
} 
interessa analisar esse desejo por uma manifestação absoluta da presença - metafísica, inclusive (ainda que sempre se dê no físico e pelo físico) -, tal como já foi feito com maestria por Jacques Derrida. ${ }^{18}$

Em todo caso, nesse retorno interessado que Artaud expressa em direção aos antigos Mitos (palavra grafada por ele sempre em letra maiúscula), bem como ao teatro de Sêneca, parece existir uma profunda desleitura daquilo que a obra desse tragediógrafo parece ter representado para a maior parte da tradição ocidental. Que se leve em conta um juízo influente como aquele expresso por Lessing, em seu livro de 1766, Laokoon [Laocoonte]:

Os heróis devem mostrar sentimento, devem exteriorizar a sua dor e permitir que a simples natureza atue sobre eles. Se eles dão mostras de adestramento ou de pressão, eles deixam o nosso coração frio e esgrimadores de coturno podem no máximo suscitar admiração. Todos os personagens das assim chamadas tragédias de Sêneca merecem essa denominação, e é a minha opinião firme que os jogos dos gladiadores foram o principal motivo pelo qual os romanos permaneceram muito abaixo da mediocridade na arte trágica. (Lessing, 2011, p. 112, trad. Márcio Seligmann-Silva)

Juízo análogo pode ser encontrado nos escritos dos principais nomes do primeiro romantismo alemão, como Friedrich Schiller e os irmãos Schlegel. ${ }^{19}$ Em suas importantes Vorlesungen über dramatische Kunst und Literatur [Cursos sobre a arte dramática e literatura], August-Wilhelm Schlegel chegou inclusive a duvidar que trabalhos de gosto tão pobre poderiam ser atribuídos a um filósofo do calibre de Sêneca:

Qualquer que tenha sido o período de que vieram as tragédias de Sêneca, elas são excessivamente pomposas e frígidas, pouco naturais tanto em caráter quanto em ação, revoltantes em sua ensandecida violação dos costumes, e tão destituídas de visão teatral que acredito jamais terem sido concebidas para sair das escolas de oradores em direção ao palco. (Schlegel, 1817, p. 27) ${ }^{20}$

Lido muitas vezes como um estoico de estilo retórico pomposo e refinado, Sêneca frequentemente viu sua obra trágica ser interpretada à luz de sua carreira política e filosófica, como mero desdobramento de suas teses estoicas. Tal corrente interpretativa talvez seja, em termos numéricos, a mais expressiva da fortuna crítica do autor, como se pode constatar a partir de um relancear de olhos sobre os títulos dos capítulos de alguns estudos dedicados recentemente à tradução de sua obra no Brasil, ${ }^{21}$ ou mesmo na abordagem de especialistas em sua obra. ${ }^{22}$

Uma polêmica estudiosa francesa, Florence Dupont, porém, estudando o teatro de Sêneca, sugeriu o caráter ritual que a tragédia latina teria para seu público em Roma. Tratando sobre a origem mítica dessa instituição, a partir do relato de historiadores como Tito Lívio (2.3-6) e Valério Máximo (2.4.4) a autora afirma o seguinte:

\footnotetext{
${ }^{18}$ Para detalhes dessa crítica, cf. Derrida, 1967b.

${ }^{19}$ Para detalhes - e referências bibliográficas - sobre essa recepção da obra de Sêneca no início do séc. XIX, na Alemanha, cf. Citti, 2016, p. 255-6.

${ }^{20}$ Aus welcher Zeit die Tragödien des Seneca nun auch seyn mögen, sie sind über alle Beschreibung schwülstig und frostig, ohne Natur in Charakter und Handlung, durch die widersinnigsten Unschicklichkeiten empörend, und so von aller theatralischen Einsicht entblößt, daß ich glaube, sie waren nie dazu bestimmt, aus den Schulen der Rhetoren auf die Bühne hervorzutreten. (Tradução nossa)

${ }^{21}$ A título de exemplo, cf. Heleno, 2006; Marchiori, 2008.

${ }^{22}$ Como Norman Pratt (1983) e Zélia de Almeida Cardoso (2005, p. 127-44), por exemplo.
} 
Os séculos passam, no ano de 396 a.C., a Peste ataca. Não é a primeira vez que Roma sofre o Flagelo divino, signo de uma ruptura entre os homens e os deuses. Os sacerdotes responsáveis pelas expiações esforçam-se, mas nenhum piaculum conhecido mostra-se eficaz. Vão procurar na Etrúria o remédio novo e serão trazidos daí espetáculos cênicos que são apresentados a Roma no interior dos Jogos Romanos, como única maneira de poder oferecê-los aos deuses. (Dupont, 1995, p. 29) 23 $^{23}$

Dupont precisa ainda que esses relatos provavelmente não têm validade histórica, mas indicam que os sangrentos ludi [jogos circenses], dentre os quais se encontrava também a tragédia romana, eram vistos como integrantes de um grupo de ritos expiatórios capazes de dar fim a uma catástrofe humana por meio do estabelecimento de uma nova ligação propiciatória com a esfera divina. Daí até a incorporação dos mitos gregos ao repertório trágico latino - sob a etiqueta de ludi Graeci [jogos gregos] - teria sido apenas um passo, segundo a estudiosa (Dupont, 1995, p. 31). O que importa nessa reconstrução das ideias que se faziam acerca das origens da tragédia em território romano, contudo, é a relação entre a Peste (como uma espécie de manifestação da falência da esfera humana fechada em si mesma), a necessidade de reconstruir essa ligação entre a humanidade e a divindade (por meio de um espetáculo dramático segundo uma conformação ritualística) e a importância assumida pelos sangrentos mitos antigos. Como se vê, o esquema da estudiosa evoca de forma bastante aproximada a proposta de Artaud.

Dupont, contudo, nega veementemente que possa existir qualquer aproximação entre sua abordagem e as aspirações do Teatro da Crueldade. Conforme a autora:

Para Artaud, a tragédia abre-se sobre mistérios proibidos, sobre um além da humanidade, que tem a ver com a loucura e o religioso. Ora, uma tendência atual dos diretores que reivindicam Artaud e a experiência dos Cenci deseja reabilitar Sêneca, fazendo dele um teatro do horror. Mas o horror do séc. XX, sem ritualismo nem dimensão religiosa, não pode ser nada mais do que o horror sórdido do cotidiano: estamos bem longe de Artaud. Aplicado a Sêneca, esse expressionismo produz apenas Grand-Guignol. (Dupont, 1995, p. 16) ${ }^{24}$

\section{E pur si muove!}

Ainda que renegue, Dupont oferece uma visão sobre a tragédia romana que apresenta inúmeras afinidades com as propostas feitas por Artaud para renovar o teatro contemporâneo. E que não se ignore a dimensão ritualística da mise-en-scène tal como proposta por ele - depois de conclamar a resistência "à linguagem e a suas fontes sordidamente [bassement] utilitárias", Artaud afirma-o de forma peremptória:

Tudo nessa forma poética e ativa de se encarar a expressão em cena leva-nos a nos desviarmos da acepção humana, atual e psicológica do teatro, para reencontrar nela a acepção religiosa e mística da qual nosso teatro perdeu completamente o sentido. (Artaud, 1964a, p. 69-70) (5 $^{25}$

\footnotetext{
${ }^{23}$ Les siècles passent, puis en 369 av. J.-C., la Peste frappe. Ce n'est pas la première fois que Rome subit ce Fléau divin, signe d'une rupture entre les hommes et les dieux. Les prêtres chargés des expiations s'affairent, mais aucun piaculum connu ne se révèle efficace. On va chercher en Étrurie un remède nouveau, et l'on en ramène des spectacles scéniques qui sont présentés à Rome à l'intérieur des Jeux Romains, seule façon de pouvoir les offrir aux dieux. (Tradução nossa)

${ }^{24}$ Pour Artaud la tragédie ouvre sur des mystères interdits, sur un au-delà de l'humanité, qui a à voir avec la folie et le religieux. Or une tendance actuelle de metteurs en scène qui se réclament d'Artaud et de l'expérience des Cenci, veut réhabiliter Sénèque en en faisant un théâtre de l'horreur. Mais l'horreur du XXe siècle, sans ritualité ni dimension religieuse ne peut être que l'horreur sordide du quotidien; nous sommes loin d'Artaud. Appliqué à Sénèque cet expressionisme ne produit que du grand-guignol. (Tradução nossa)

${ }^{25}$ Tout dans cette façon poétique et active d'envisager l'expression sur la scène nous conduit à nous détourner de l'acception humaine, actuelle et psychologique du théâtre, pour en retrouver l'acception religieuse et mystique dont notre théâtre a complètement perdu le sens. (Tradução nossa)
} 
Deixando de lado, porém, o possível significado por trás da recusa de Dupont, sua teoria sobre o imaginário romano acerca da tragédia, bem como sua utilização e sua origem num contexto ritualístico, apontam para a direção que talvez permita remontar a "desleitura" operada por Artaud do teatro senequiano (talvez antes uma tresleitura do que uma desleitura). ${ }^{26}$ Contrariando abertamente a corrente interpretativa majoritária da obra desse autor - que via nele o refinamento e o artificialismo de um estilo retórico colocado a serviço de proposições pedagógicas, sobretudo de caráter estoico -, ele reivindicaria para Sêneca uma tragédia profundamente imbricada com os mistérios da existência humana, capaz de exprimir segredos proibidos e sagrados, ao dispor de maneira cruel - e imersa no mais profundo ritualismo - o corpo em cena. ${ }^{27}$

Nos inúmeros textos reunidos em Le théâtre et son double lO teatro e seu duplo], essa rede de associações já se encontra bem definida por Artaud no que tange à sua proposta de renovação do teatro. Contudo, sua relação com a obra de Sêneca é expressa de maneira ainda mais completa e instigante numa carta que ele envia a Jean Paulhan, em 16 de setembro de 1932. Um estudo recente sobre a relação de Artaud com os clássicos reúne inúmeros documentos de difícil acesso, organizando as referências clássicas em sua obra, e a próxima citação será feita a partir do texto que consta nesse estudo: ${ }^{28}$

Estou lendo Sêneca, do qual me parece louco que se possa confundi-lo com um moralista preceptor de sei lá que tirano da decadência - ou então o Preceptor era este, mas envelhecido, desesperançado da magia. Em todo caso, ele me parece o maior autor trágico da história, um iniciado nos Segredos e que soube fazê-los passar em palavras melhor do que Ésquilo. Choro enquanto leio seu teatro de inspirado e sinto aí, sob o verbo, sílabas crepitarem - da mais atroz maneira - a fervura transparente das forças do caos. E isso me faz pensar em algo: uma vez curado, tenho a intenção de organizar leituras dramáticas - para um homem que nega o texto no teatro, isso não será nada mal -, leituras públicas em que lerei as Tragédias de Sêneca, e todos os comanditários possíveis do Teatro da Crueldade serão convocados. Não se pode mais facilmente encontrar um exemplo escrito daquilo que se pode entender por crueldade no teatro do que em todas as Tragédias de Sêneca, mas sobretudo em Atreu e Tiestes. Visível no Sangue, ela é ainda mais no espírito. Esses monstros são cruéis como apenas as forças cegas podem ser e apenas há teatro, eu penso, no grau ainda não humano... Em Sêneca as forças primordiais levam a escutar seu eco na vibração espasmódica das palavras. E os nomes que designam segredos e forças designam-nos no trajeto dessas forças e com sua força de extração e destruição. (Artaud apud Sánchez León, 2007, p. 95) ${ }^{29}$

\footnotetext{
${ }^{26}$ A noção de desleitura tem relação com os deslocamentos operados na leitura de um texto a fim de deformá-lo e conformá-lo a certas preconcepções monologizantes que se fazem acerca do mesmo. Já a noção de tresleitura sugere a possibilidade deslocar um texto para além de seus limites estritos, iluminando a existência de pontos cegos nesse texto, mas a partir de uma leitura atenta dele próprio. Para mais detalhes desses "conceitos", a partir das leituras que Platão faz da obra de Homero, cf. Silva, 2017.

${ }^{27}$ Essa concepção extrapola a interpretação corrente sobre as tragédias de Sêneca, mesmo na abordagem antropológica, de viés ritualista, tal como proposta por Florence Dupont. Sua intuição geral, contudo, indica um caminho que tem sido explorado cada vez com mais proveito pela crítica contemporânea.

${ }^{28}$ Para mais detalhes, cf. Sánchez León, 2007.

${ }^{29}$ Je suis en train de lire Sénèque, dont il me paraît fou qu'on puisse le confondre avec le moraliste précepteur de je ne sais quel tyran de la décadence - ou alors le Précepteur était celui-ci, mais vieilli, désespéré de la magie. Quoi qu'il en soit celui-ci me paraît le plus grand auteur tragique de l'histoire, un initié aux Secrets et qui mieux qu'Eschyle a su les faire passer dans les mots. Je pleure en lisant son théâtre d'inspiré, et j'y sens sous le verbe des syllabes crépiter de la plus atroce manière le bouillonnement transparent des forces du chaos. Et ceci me fait penser à quelque chose: une fois guéri j'ai l'intention d'organiser des lectures dramatiques - pour un homme qui nie le texte au théâtre ce ne sera pas mal -, lectures publiques où je lirai les Tragédies de Sénèque, et tous les commanditaires possibles du Théâtre de la Cruauté seront convoqués. On ne peut mieux trouver d'exemple écrit de ce qu'on peut entendre par cruauté au théâtre que dans toutes les Tragédies de Sénèque, mais surtout dans Atrée et Thyeste. Visible dans le Sang, elle l'est encore plus dans l'esprit. Ces monstres sont méchants comme
} 
Levando em conta esse posicionamento idiossincrático perante a recepção tradicional da tragédia senequiana, não é de se estranhar que Artaud tenha se manifestado de maneira tão enfática contra a proposta de um dramaturgo como Unamuno e seu "teatro desnudo". Na tradução e adaptação que o espanhol propôs à Medea de Sêneca (montagem que Artaud presencia no México em 1936 e sobre a qual escreve um compte-rendu bastante violento ${ }^{30}$ ), o lado monstruoso do mito the parece mitigado nesse espetáculo em proveito de uma mise-en-scène miseravelmente estilizada. Aspectos da tradução em prosa de Unamuno não são explicitamente tratados, mas a performance da atriz principal - Margherita Xirgu - e o trabalho de montagem são criticados duramente. É evidente que as propostas de Artaud para o Teatro da Crueldade, a partir de uma leitura muito particular de Sêneca, não poderiam dar margem a uma apreciação diferente do teatro de Unamuno. ${ }^{31}$

Acerca disso, um estudioso recente da recepção do Sêneca Tragicus em autores do séc. XIX e inícios do XX escreveu o seguinte:

O poder dramático da palavra, junto com uma concentração sobre famílias pegas em conflitos destrutivos e ciclos de vingança (chegando até o incesto e o canibalismo), com um jogo entre os papéis de vítima e perpetrador, são o que Antonin Artaud aprecia em Sêneca: ele considera seu drama como um modelo primordial para suas teorias sobre o "Teatro da crueldade" - um teatro que deveria perturbar como uma peste - e também para seus dramas (o não terminado Le Supplice de Tantale [O Suplício de Tântalo], originalmente intitulado Atrée et Thyeste [Atreu e Tiestes], e Les Cenci [Os Cenci], 1935). (Citti, 2016, p. 272-3). ${ }^{32}$

Segundo o estudioso, um aspecto fundamental de inúmeras das tragédias senequianas (e que se encontra entre os interesses profundos de Artaud) era um elemento sobrenatural - ultrapassando em larga medida os limites do próprio teatro -, que ele entendia como o fatum [fado]. Na versão de Sêneca do mito de Tiestes e Atreu, por exemplo, a sombra de Tântalo e as Fúrias cumpririam esse papel, transcendendo a vontade das personagens e conduzindo-as forçadamente à ação. Numa passagem emblemática dessa tragédia, Atreu afirma:

Não sei o que há de maior e mais amplo do que de costume

E que incha em meu espírito além dos limites do humano

E instiga as preguiçosas mãos. Não sei o que é, mas é algo poderoso.

(Thyestes, vv. 267-70). ${ }^{33}$

\footnotetext{
seules les forces aveugles peuvent l'être, et il n'y a théâtre, je pense, qu'au degré pas encore humain... Dans Sénèque les forces primordiales font entendre leur écho dans la vibration spasmodique des mots. Et les noms qui désignent des secrets et des forces les désignent dans le trajet de ces forces et avec leur force d'arrachement et de broiement. (Tradução nossa)

${ }^{30}$ Cf. Sánchez León, 2007, p. 101-3.

${ }^{31}$ Para mais detalhes da leitura que Unamuno faz de Sêneca, cf. Citti, 2016, p. 267-71.

32 The dramatic power of the word, together with a focus on families caught in destructive conflicts and cycles of revenge (extending even to incest and cannibalism), with an interplay between the roles of victim and perpetrator, are what Antonin Artaud appreciates in Seneca: he considers his drama as a prime model for his theories on the "Theater of cruelty" - a theater that should disturb like a plague - and also for his dramas (the unfinished Le Supplice de Tantale [Torment of Tantalus], originally entitled Atrée et Thyeste [Atreus and Thyestes], and Les Cenci [The Cenci], 1935). (Tradução nossa)

${ }^{33}$ Nescioquid animo maius et solito amplius/ supraque fines moris humani tumet/ instatque pigris manibus—haud quid scio, sed grande quiddam est. (Tradução nossa)
} 
O teatro tal como compreendido por Artaud deveria ser a experiência, para além das próprias palavras, daquilo que afirmam esses versos de Sêneca. A manifestação de uma força sobre-humana no espaço cênico, capaz de transportar tanto atores quanto público para uma esfera de contato com o divino, levando-os a uma ação pouco consciente de si, mas profunda e poderosa. Que os velhos Mitos pudessem ser uma das maneiras de se chegar a esse novo ideal, valendo-se da crueldade primitiva em que muitos deles estão fundamentados, é algo que aparece reiteradamente em seus escritos e projetos para a cena. A possibilidade de inspirar-se nesses Mitos a fim de forjar outros, ainda mais cruéis e macabros - como o autor faz com Les Cenci IOs Cenci], a partir do próprio Thyestes - é uma ideia sempre defendida por Artaud e que aparece reiteradas vezes em seus escritos.

Numa carta de 9 de novembro de 1932, endereçada também a Jean Paulhan - e incluída em Le théâtre et son double [O teatro e seu duplo] -, o autor afirmava:

O teatro deve igualar-se à vida, não à vida individual, a esse aspecto individual da vida no qual triunfam os CARACTERES, mas a um tipo de vida liberada, que varre a individualidade humana e no qual o homem não é nada mais do que um reflexo. Criar Mitos, eis o verdadeiro objeto do teatro, traduzir a vida sob seu aspecto universal, imenso, e extrair dessa vida imagens em que adoraríamos nos reencontrar.

E chegar - fazendo isso - a uma espécie de semelhança geral e tão poderosa que ela produza instantaneamente seu efeito.

Que ela nos libere, a nós, em um Mito que tenha sacrificado nossa pequena individualidade humana, como Personagens vindos do Passado, com forças reencontradas no Passado. (Artaud, 1964f, p. 181) 34 $^{34}$

A relação de Artaud com as tragédias de Sêneca são profundas e extremamente importantes para o desenvolvimento da dramaturgia contemporânea. Ainda que os especialistas possam acusá-lo de praticar uma desleitura da obra desse importante filósofo, político e poeta latino - desconsiderando aspectos fundamentais de seu contexto histórico, por exemplo -, é certo que o autor francês pratica um retorno interessado em sua leitura do Sêneca Tragicus: encontra nele as sementes daquilo que defenderia como o verdadeiro motor da ação dramática, qual seja, a crueldade. Nesse sentido, e levando em conta os aportes recentes trazidos pela bibliografia especializada na tragédia latina, seria possível sugerir que Artaud treslê Sêneca, ou seja, lê si mesmo para além do próprio autor. Em sua tresleitura, Artaud inaugura um novo capítulo na recepção de Sêneca, cujos desdobramentos contam ainda com o importante estudo de Florence Dupont sobre a dimensão ritualística da tragédia romana e com muito do que se propôs a partir daí.

\footnotetext{
${ }^{34}$ Le théâtre doit s'égaler à la vie, non pas à la vie individuelle, à cet aspect individuel de la vie où triomphent les CARACTĖRES, mais à une sorte de vie libérée, qui balaye l'individualité humaine et où l'homme n'est plus qu'un reflet. Créer des Mythes voilà le véritable objet du théâtre, traduire la vie sous son aspect universel, immense, et extraire de cette vie des images où nous aimerions à nous retrouver./ Et arriver ce faisant à une espèce de ressemblance générale et si puissante qu'elle produise instantanément son effet./ Qu'elle nous libère, nous, dans un Mythe ayant sacrifié notre petite individualité humaine, tels des Personnages venus du Passé, avec des forces retrouvées dans le Passé. (Tradução nossa)
} 


\section{Referências}

ARTAUD, A. La mise en scène et la métaphysique. In: Le théâtre et son double. Paris: Gallimard, 1964a, p. 49-72.

Le théâtre de la cruauté. In: Le théâtre et son double. Paris: Gallimard, 1964b, p. 131-6.

Le théâtre de la cruauté (Premier manifeste). In: Le théâtre et son double. Paris: Gallimard, 1964c, p. 137-56.

. Le théâtre et la culture. In: Le théâtre et son double. Paris: Gallimard, 1964d, p. 11-20.

Le théâtre et la peste. In: Le théâtre et son double. Paris: Gallimard, 1964 e, p. 21-48.

Lettres sur le langage. In: Le théâtre et son double. Paris: Gallimard, $1964 f$, p. 163-88.

CARDOSO, Z. A. O tratamento das paixões nas tragédias. In: Estudos sobre as tragédias de Sêneca. São Paulo: Alameda, 2005b, p. 127-44.

CITTI, F. Nineteenth- and Early Twentieth-Century Receptions of Seneca Tragicus. In: DODSON-ROBINSON, E. (Ed.). Brill's Companion to the Reception of Senecan Tragedy: Scholarly, Theatrical and Literary Receptions. Leiden; Boston: Brill, 2016, p. 255-81.

DERRIDA, J. La parole soufflée. In: L'écriture et la différence. Paris: Éditions du Seuil, 1967a, p. 253-92.

Le théâtre de la cruauté et la clôture de la représentation. In: L'écriture et la différence. Paris: Éditions du Seuil, 1967b, p. 341-68.

DODSON-ROBINSON, E. (Ed.). Brill's Companion to the Reception of Senecan Tragedy: Scholarly, Theatrical and Literary Receptions. Leiden; Boston: Brill, 2016.

DUPONT, F. Les monstres de Sénèque. Pour une dramaturgie de la tragédie romaine. Paris: Belin, 1995.

HELENO, J. G. Hércules no Eta: Uma tragédia estóica de Sêneca. 2006. 308 f. Tese (Doutorado em Letras) - Departamento de Letras Clássicas e Vernáculas da Faculdade de Filosofia, Letras e Ciências Humanas, Universidade de São Paulo, São Paulo. 2006.

KLEIN, G. R. O Édipo de Sêneca: Tradução e estudo crítico. 2005. 156 f. Dissertação 
(Mestrado em Linguística) - Instituto de Estudos da Linguagem, Universidade de Campinas, Campinas. 2005.

LESSING, G. E. Laocoonte ou Sobre as fronteiras da Poesia e da Pintura: Com esclarecimentos ocasionais sobre diferentes pontos da história da arte antiga. Introdução, tradução e notas de Márcio Seligmann-Silva. São Paulo: Iluminuras, 2011.

MARCHIORI, L. A. Hercules furioso de Sêneca: Estudo introdutório, tradução e notas. 2008. 165 f. Dissertação (Mestrado em Letras) - Departamento de Letras Clássicas e Vernáculas da Faculdade de Filosofia, Letras e Ciências Humanas, Universidade de São Paulo, São Paulo. 2008.

PRATT, N. Seneca's drama. Chapel Hill: The University of North Carolina Press, 1983.

REMSHARDT, R. Seneca Our Contemporary: The Modern Theatrical Reception of Senecan Tragedy. In: DODSON-ROBINSON, E. (Ed.). Brill's Companion to the Reception of Senecan Tragedy: Scholarly, Theatrical and Literary Receptions. Leiden; Boston: Brill, 2016, p. 282-302.

SÁNCHEZ LEÓN, J. C. L'Antiquité grecque dans l'oeuvre d'Antonin Artaud. Besançon: Institut des Sciences et Techniques de l'Antiquité, 2007, p. 5-116.

SCHLEGEL, A. W. Ueber dramatische Kunst und Literatur. Zweyte Ausgabe. Zweyte Theil. Heidelberg: Ley Mohr und Winter, 1817.

SÊNECA. Annaei Senecae Tragoediae. Oxford: Clarendon Press, 1986.

SÊNECA. Tragoediae. Rudolf Peiper (Ed.). Leipzig: Teubner, 1921.

SÊNECA. Tragédias: A loucura de Hércules; As troianas; As fenícias. Tradução, introdução, apresentações e notas de Zélia de Almeida Cardoso. São Paulo: Editora WMF Martins Fontes, 2014.

SILVA, R. G. T. Treslendo a citação (República): de Platão a Homero. Nuntius Antiquus, Belo Horizonte, v. 13, n. 1 (2017), p. 205-226.

Recebido em: 02/06/2018 Aprovado em: 30/10/2018 